\title{
Neologismos Heterodiscursivos: poesia de Arnaldo Antunes na era do Antropoceno
}

\author{
Sandra Mina Takakura \\ Universidade do Estado do Pará (UEPA), Belém, Pará, Brasil \\ sandramita@hotmail.com \\ http://orcid.org/0000-0002-6882-0174
}

DOI: http://dx.doi.org/10.21165/el.v47i1.1911

\begin{abstract}
Resumo
Este artigo apresenta os resultados de estudo sobre neologismos em uma pequena seleção de obras da exposição intitulada Luzescrita (2013-), composta por poemas de Arnaldo Antunes, montagem e registros permanentes em fotografia, de Fernando Lazslo. Os trabalhos selecionados resultam da convergência dos processos de criação literária e artística, em estreita relação com os processos linguísticos. O estudo adota a expansão conceitual de heterodiscurso de Bakhtin (2015), a fim de incluir os distintos estilos, linguagens e sistemas axiológicos em mídias diferentes no embate semântico das criações neológicas. Os trabalhos resultam das variadas interações entre humanos e tecnologia (LATOUR, 2005), na era do Antropoceno.
\end{abstract}

Palavras-chave: neologismo; Antropoceno; Bakhtin; Latour; Luzescrita.

\section{Heteroglot Neologisms: Arnaldo Antunes's Poetry in the Anthropocene Era}

\begin{abstract}
This article presents the results of a study on neologisms in a short selection of works from the exposition entitled as Luzescrita (2013-), composed by some poems, by Arnaldo Antunes, assembly and permanent registers on photography, by Fernando Lazslo. The selected works for this study result from the convergence of the processes of literary and artistic creations, with narrow relation with linguistic processes. The study adopts the conceptual expansion of heteroglossia, by Bakhtin (2015) to render distinct styles, languages, axiological systems in distinct medias in the semantic conflict in the neological creations. The study involved also the scrutiny of the semantic field. The works result from the interactions between human and technology (LATOUR, 2005), in the Anthropocene era.
\end{abstract}

Keywords: neologism; Anthropocene; Bakhtin; Latour; Luzescrita.

\section{Contexto de investigação}

Notório pela sua atuação na música e na literatura, Arnaldo Antunes representa esse ser pós-moderno que produz obras que desafiam as divisões distintas dos campos de conhecimento. Pode-se afirmar que sua poesia é impregnada de musicalidade e sua música é permeada de poeticidade, estabelecendo um diálogo com a literatura. Sua produção inspira-se nos mais diversos movimentos e manifestações culturais anteriores.

Essa linguagem híbrida que se verifica em sua poesia e música, através de pontos de convergência entre os campos musicais e literários, torna-se ainda mais complexa quando estabelece diálogo com as artes plásticas. Esse aspecto verbovocovisual de sua obra permite o estudo nos mais variados campos de pesquisa, como a Teoria literária, Linguística, Artes, Música, sob inúmeras abordagens. A escolha por uma área ou outra 
implica necessariamente um recorte, lançando luz a determinados pontos ainda não iluminados, possibilitando múltiplas leituras, sem que o objeto de investigação se esgote em suas potencialidades interpretativas.

Seu projeto, intitulado Luzescrita, em coautoria com o fotógrafo Fernando Lazslo e o artista visual Walter Silveira, sob a curadoria de Daniel Rangel, teve início em 2002. $\mathrm{E}$, atualmente, conta com cerca de 60 obras que realizam a mescla entre a poesia em estilo neoconcreto e os processos de produção artística via tecnologia, vislumbrados por Augusto de Campos na introdução de Poetamenos (1953). ${ }^{1}$

$\mathrm{Na}$ instalação, os objetos-arte representam o resultado dos processos convergentes que aliam as experimentações poéticas centradas na palavra ou em suas combinações minimalistas e o meio material utilizado para produzi-los. O projeto, concebido na pósmodernidade, vale-se do uso eflúvio de linguagens que entram em embate para a constituição de discursos renovados, que por sua vez levam à própria reflexão acerca dos meios por meio dos quais as obras foram produzidas.

São obras contemporâneas que respondem à crise no campo da arte, expresso por Artur C. Danto em After the end of art (1997). Ao declarar o fim da arte concebida enquanto uma linha de progressão histórica e estética, Danto (1997) questiona a própria noção de arte, realizando um amplo estudo das produções recentes e demonstra a libertação dos processos criativos de concepção de arte no período contemporâneo. Lucia Santaella (2013, p. 11) descreve tal processo a partir de Danto (1997) como diverso, permitindo o uso de inúmeras técnicas e suportes materiais:

Entre traços mais relevantes, mas inegavelmente visíveis dessa arte [contemporânea] encontram-se a pluralidade, a multiplicidade, a diversidade. Quaisquer materiais, quaisquer suportes, quaisquer técnicas ou tecnologias, quaisquer métodos, quaisquer resultados podem se candidatar ao panteão das artes.

As obras concebidas nesse projeto debruçam-se a experimentar na arte e na literatura, respondendo também à crise da palavra, preconizada, entre outros, por Fredric Jameson (1985), em Pós-Modernidade e Sociedade de Consumo, que anuncia o esvaziamento dos sentidos das metáforas, com o argumento de que as produções atuais fazem o uso excessivo de referências às obras produzidas anteriormente. Por conseguinte, as repetições metafóricas ocasionam a inevitável perda de sentidos das palavras. O aspecto ressaltado pelo teórico como esvaziamento semântico ocorre na concepção das obras a serem estudadas. No entanto, novos sentidos são agregados no contexto da obra que faz uso de novos suportes materiais. O estudo desses sentidos renovados demanda, no entanto, a recuperação dos sentidos dicionarizados que foram transgredidos no processo de concepção da obra para o mapeamento dos efeitos expressivos através de contraste

As criações verbais, verificadas na seleção de obras, têm o seu campo semântico alterado também pelo meio material da produção em si, resultando em poemas-objetos, poemas-vídeos, ocasionando a ocorrência de linguagens híbridas de mídias distintas. Bakhtin (2015, p. 84), em A Teoria do Romance I: a estilística, traça a mescla de "dois enunciados, estilos, linguagens e horizontes", que podem ser vislumbrados como "dois

\footnotetext{
${ }^{1}$ As informações técnicas das obras como material e dimensões serão citadas diretamente dos encartes da publicação do evento em 2013 e da retificação no encarte que acompanha a exposição em 2017.
} 
sentidos heterodiscursivos, dois acentos", enquanto linguagem híbrida, na constituição do romance. A expansão teórica para abarcar os corpora desse estudo se explicam uma vez que o heterodiscurso pode ser compreendido enquanto discurso entrecortado pelo discurso do outro, outra esfera discursiva ou outro campo de especialidade (BAKHTIN, 2015). As produções que compõem a exposição transcendem o plano bidimensional do papel, tradicionalmente adotado na escrita literária, partindo para o hibridismo de duas grandes áreas de conhecimento, a literatura e a arte, podendo ser recepcionadas como poesia e como arte em sua composição tridimensional ou digital.

A linguagem poética, observada nas criações lexicais, e os meios materiais que a concebem compartilham o elemento comum que é a luz em suas variadas manifestações, disponíveis por meio da tecnologia, como: lâmpadas, fogo, luz cibernética ou digital.

Marchall McLuhan (1964), em Os Meios de comunicação como extensões do homem, explica que a luz elétrica constitui o único meio que não carrega a mensagem, somente o que ela ilumina torna-se mensagem: "A luz elétrica é informação pura. É algo assim como um meio sem mensagem, a menos que seja usada para explicitar algum anúncio verbal ou algum nome" (MCLUHAN, 1964, p. 22). Santaella (2013, p. 8) assim explica a noção do teórico da comunicação: "a luz é um meio despido de conteúdo, pois seu conteúdo é tudo aquilo que ela ilumina. É o meio de todos os meios, paradoxalmente invisível para tornar possível o visível".

Neste estudo, adota-se a visão de que as escolhas dos meios refletem e refratam as interações humanas com objetos que ocorreram ao longo de nosso processo civilizatório, na constituição de sociedades. Portanto, a partir do momento que se considera a luz gerada por meios materiais como lâmpadas e fogo, a própria escolha material passa a carregar uma mensagem. A relação que o indivíduo estabelece com a tecnologia é apenas um nó na grande rede de relações que o homem estabelece de forma contínua com a natureza, a cultura e a sociedade, que não estão necessariamente em oposição, como explica Bruno Latour (2005) em Reassembling the Social: An Introduction to Actor-Network - Theory.

Outro aspecto notável é a concepção da obra por meio da tecnologia, para as produções "escritas", saindo da experiência comum do pincel, caneta e lápis nesses processos, instigando o público a repensar os meios utilizados como extensões de corpos sem seus processos criativos. Tal visão leva à reflexão acerca da constituição de agências dos próprios materiais, uma vez que estes agregam discursos políticos, em sentido amplo, nas concepções das obras.

O estudo realizado na contemporaneidade se insere em um contexto mais amplo da era do Antropoceno, considerado como o período em que o homem passou a acumular sedimentos nas camadas do globo terrestre, resultado do desenvolvimento das tecnologias (CRUTZEN; STOERMER, 2000; ZALASIEWICZ et al., 2010, 2008).

Os meios agregam sentidos às criações estilísticas, restringindo os campos semânticos dos signos, direcionando-os a determinados usos no contexto das produções e instalações das obras. Assim, há dois sistemas axiológicos, duas linguagens e dois estilos, portanto, o heterodiscurso que decorre da intersecção entre a literatura e as artes é levado em conta para o estudo das criações neológicas. E, devido ao hibridismo, resultante da convergência dos meios verbal e material, a noção de criações neológicas foi expandida de forma a incluir também a escolha do material no estudo semântico dos neologismos. 


\section{Criações Neológicas}

André Mirambel² (1959 apud GUILBERT, 1975) explica a criação artística como sendo aquela que não encontra limites em sua concepção ao passo que as criações literárias podem ser processadas de duas maneiras. A primeira aproxima-se da criação artística e dá asas à fantasia sem se ater a limites. E a segunda, cuja forma de produção guarda uma relação estreita com a criação linguística, sendo pautada na expressividade, é cerceada pela comunicabilidade em uma dada comunidade linguística. As obras a serem analisadas mesclam as linguagens artísticas e literárias, estabelecendo uma relação de proximidade com as criações linguísticas, estando por esse aspecto em conformidade com as restrições impostas pelo próprio sistema da língua. Guilbert (1975, p. 42, tradução nossa), a partir de Mirambel, define o texto literário:

É dito texto literário toda produção escrita no enquadre de certo gênero, tendo lançado em uma obra editada e difundida de acordo com um aparelho próprio à sociedade onde vivemos, codificada de acordo com certa hierarquia estabelecida por certa crítica que possui suas regras estéticas e ideológicas, e de acordo com certa difusão para um público de leitores, em função das condições econômicas e sociais próprias ao mercado de livros. ${ }^{3}$

Contudo, o teórico expande o contexto de ocorrência dos neologismos literários a toda atividade verbal realizada por meio de texto escrito. Inclui dessa forma toda interação, que envolva interlocutores, e cita textos na imprensa escrita e enunciados, difundidos via rádio e televisão, que são previamente escritos, visando à oralização frente a um determinado público (GUILBERT, 1975). Para o teórico, a ênfase recai sobre o processo de recepção de um texto ou enunciado por um público, que permite certa liberdade criativa, respeitando o limite da comunicabilidade estabelecida pela língua comum entre os interlocutores.

A partir dessa noção inclusiva acerca do contexto de ocorrência de neologismos literários, pensa-se na expansão teórica para abarcar os meios dos objetos-arte, como a fotografia e o vídeo nos quais são evidenciadas experimentações linguísticas. $\mathrm{O}$ efeito expressivo das criações observado nesses objetos sobre um determinado público configura-se como uma interação. Tal movimento percorre um circuito de mercado de artes experimentais, composto por críticos, artistas e público consumidores.

Quanto aos neologismos, Guilbert (1975) os delimita de três maneiras. Os neologismos denominativos centrados no referente visam comunicar de forma precisa uma informação, são decorrentes dos avanços tecnológicos e da necessidade de nomear as invenções, e possivelmente serão incorporados ao léxico de uma língua, figurando em dicionários. Já os neologismos estilísticos, criações que visam à expressividade e ao efeito de sentido em contextos descritos anteriormente, raramente são incorporados ao acervo lexical de uma língua. Há ainda as criações neológicas que podem figurar nas interações do dia a dia, que não despertam nenhum caráter de novidade, apesar de provocarem

\footnotetext{
${ }^{2}$ MIRAMBEL, A. Essai sur la création linguistique. Journal de psychologie normale et pathologique, Paris, n. 4, p. 385-415, oct./dec. 1959.

3 "Est dit texte littéraire toute production écrite dans le cadre d'un certain genre, ayant paru dans un ouvrage édité et diffusé selon l'appareil propre à la société où nous vivons, codée selon une certaine hiérarchie établie par une certaine critique qui a ses règles esthétiques et idéologiques, et d'après une certaine diffusion dans un public de lecteur, en fonction des conditions économiques et sociales propres au marché du livre" (GUILBERT, 1975, p. 42).
} 
expansões ou restrições nos campos semânticos das palavras. São considerados neologismos por não figurarem no dicionário, sendo frequentemente apreendidos enquanto sintagmas, no contexto de uso.

Neste estudo, o enfoque será o neologismo estilístico que possui necessariamente o caráter de novidade, considerando o meio através do qual o poema é concebido. Ressalta-se o duplo caráter de novidade à criação lexical, pois o campo semântico inclui também o sentido agregado pelo material da obra, que não figura especificamente no dicionário.

\section{Estudo da Expressividade}

Os objetos escolhidos centram-se em torno do processo de formação vocabular não concatenada, conhecida comumente como cruzamento vocabular. Gonçalves e Almeida (2007) destacam três processos de formação que correspondem também às operações semânticas: entranhamento ou interposição; combinações de bases truncadas e analogia lexical com rearranjo fonológico da palavra fonte. Margarida Basílio (2010) parte do primeiro processo de formação para delinear a noção de "fusão vocabular expressiva", constituída por uma base e um qualificador:

O esquema correspondente à formação de fuves [fusão vocabular expressiva] pode ser descrito como sendo a incorporação de um qualificador a uma palavra base de fonologia semelhante, de modo que (a) o significado da palavra base é modificado pelo significado do qualificador; e (b) o qualificador é reconhecido através de uma pequena alteração fonológica na palavra base. (BASÍLIO, 2010, p. 203-204, grifo nosso).

A expressividade é plenamente realizada quando a relação entre a base e o qualificador é percebida pelo leitor. Em produções literárias, contudo, essa relação nem sempre é clara; na poesia, por exemplo, as relações entre ideias, longe de serem organizadas de forma que uma se subordine à outra, frequentemente se organizam através de relações de coordenação.

A obra Sempressa (2002), observada na Figura 1, foi concebida através de um processo artístico efêmero, sendo posteriormente registrada em fotografia. Partiu-se de uma "placa de policarbonato preta, recortada, iluminada com Dedolight, projetada em quina de parede branca" (ANTUNES; LAZSLO; SILVEIRA, 2013, p. 94). Sua montagem e registro fotográfico foram realizados por Lazslo em meio analógico, em filme 4x5 Kodak 6118 e Tri-X, com revelação normal D 76 e E 6 e impressão em lambda na dimensão $142 \mathrm{~cm}$ x $102 \mathrm{~cm}$. 


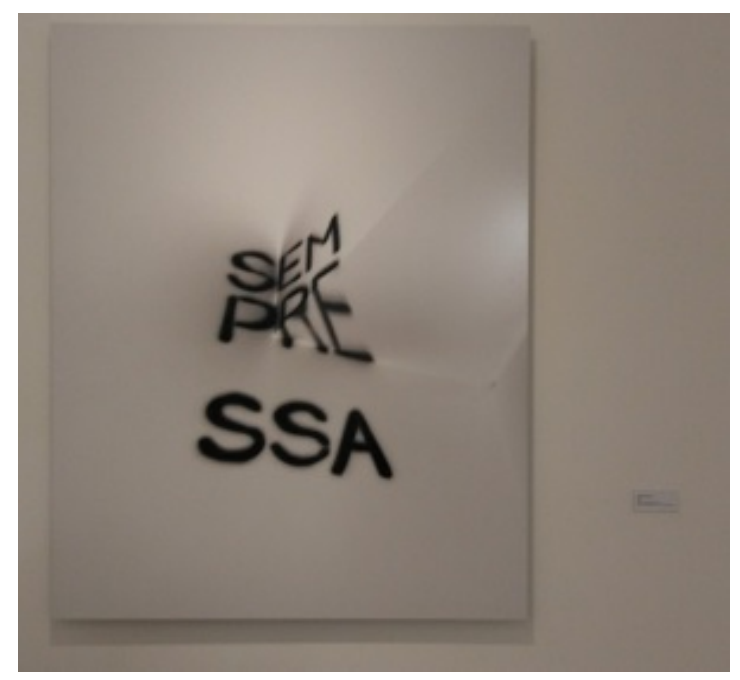

Figura 1. Sempressa

Fonte: Acervo pessoal

O processo parte do recorte do material na forma de letras e, sendo iluminado, uma escrita é projetada sobre a parede. A escrita resulta de um efeito de contraste da projeção escura sobre a parede branca. Desmistifica-se, dessa forma, a associação da luz à claridade e a escuridão à área não penetrada pela luz, no efeito de projeção de escrita de luz escura.

A poesia pode ser explicada através de processos que se sobrepõem, como a lexicalização operada por meio da justaposição das lexias "sem pressa" ou da aglutinação em "sempre essa", ou ainda, através da fusão vocabular sempressa > sempre + impressa ou sempressa $>$ sem + impressa. Essa obra inova com a projeção escura que lembra uma impressão, realizada do chão bidimensional à coluna tridimensional em uma escrita em ângulo de 90 graus em relação ao chão.

O conceito da obra quebra, dessa forma, a noção de literatura impressa em superfícies planas em duas dimensões. Vale-se desta forma da mobilidade da luz sempre acompanhada da sombra, que ocorre sobre as superfícies tridimensionais ao longo do dia, realizando a sua escrita, em seu próprio tempo, sem pressa, assim como, sem atraso.

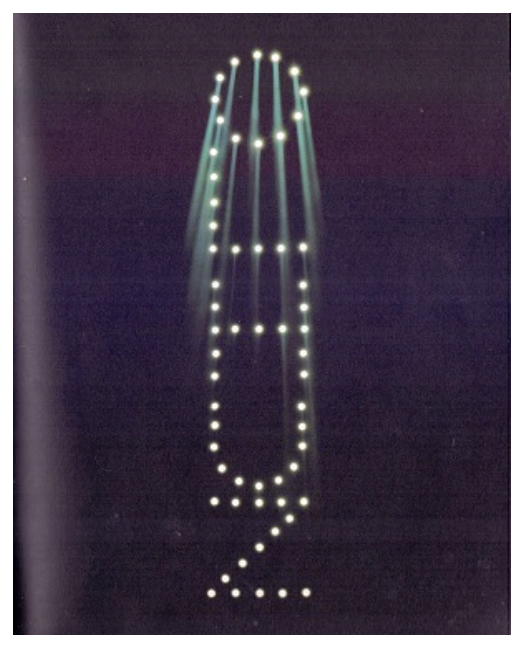

Figura 2. Olhuz

Fonte: Encarte da exposição de 2013 (imagem escaneada) 
O processo de concepção da obra Olhuz (2002), Figura 2, explica-se a partir da "placa de policarbonato preta furada com broca elétrica, iluminada com fresnel de $2.000 \mathrm{w}$ ". A montagem e a fotografia de Lazslo foram realizadas com efeitos de "baforadas de cigarro" sopradas em frente ao objeto, com registro por meio analógico, em filme 4x4 Kodak 6118 e impressão em metacrilato, na dimensão $40 \mathrm{~cm}$ x $50 \mathrm{~cm}$ (ANTUNES; LAZSLO; SILVEIRA, 2013). O processo de escrita foi realizado com pontas de brocas que efetuaram furos na placa, portanto, por meio da interação entre o homem e a tecnologia.

A escrita da luz é evidenciada pelo contraste entre a luz e a sombra, do revelado e do velado entrando na composição da mensagem. Deste modo, a luz assume dupla função, pois revela ao mesmo tempo em que oculta. $O$ efeito da fumaça de cigarro permite visualizar os caminhos percorridos pela luz em dado instante, compondo um processo efêmero, que se torna permanente através do registro fotográfico. A escrita verbal pode ser explicada pelo processo de cruzamento vocabular olhuz $>$ olhos + luz. O olho observa a luz que percorre cada orifício na chapa de acrílico, que, por sua vez, representa um ponto aberto e iluminado. A obra retrata o encontro do olho com a luz.

No dizer popular, os olhos são "a janela para a alma", e representam o acesso para a verdadeira índole do indivíduo. A obra "olhuz" simula vários olhos abertos que emanam luz. No entanto, permitem apenas serem observados, sem o acesso à alguma forma de índole ou alma.

O poema Imagigabytes (2002) é uma composição formada por quadros produzidos a partir de "placa de policarbonato preta furada com broca elétrica" que foi iluminada por "lanterna Sure Fire, com a luz direcionada para a lente da câmera" (ANTUNES; LAZSLO; SILVEIRA, 2013, p. 96). O painel em exposição é composto por 9 fotos com dimensões $42 \mathrm{~cm}$ x $32 \mathrm{~cm}$ e impressões em metracrilato, produzidas por meio analógico, em filme 4x5 Kodak 6105 e Tri-X, tendo revelações normais em E6, C41 e D76 (ANTUNES; LAZSLO; SILVEIRA, 2013).

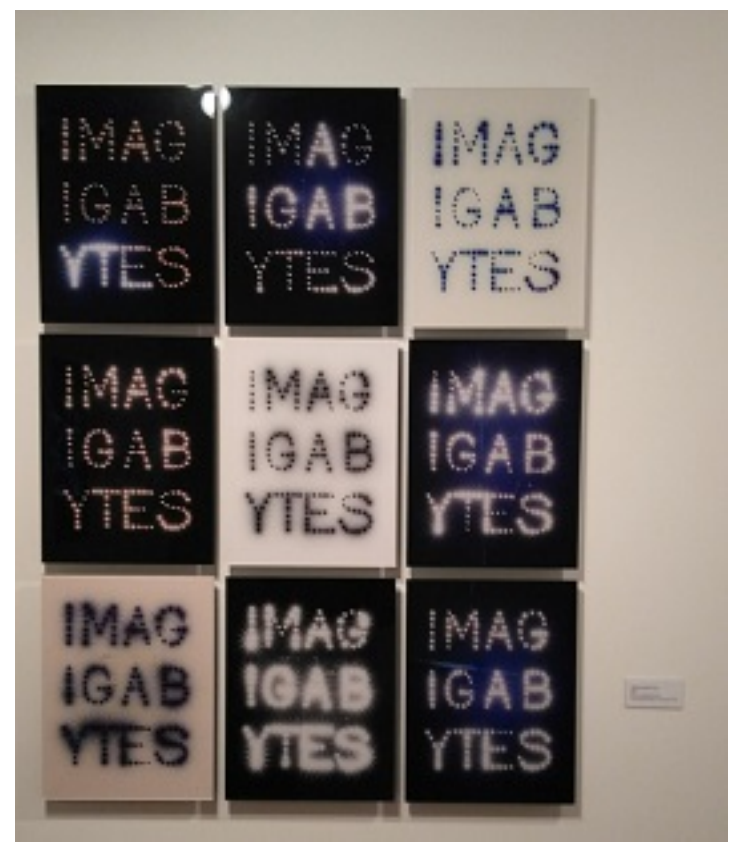

Figura 3. Imagigabytes

Fonte: Acervo pessoal 
O poema de Arnaldo recebeu a montagem e fotografia de Lazslo, Figura 3. A criação lexical "imagigabytes" pode ser explicada por meio da fusão vocabular imagigabytes $>$ imagine + giga + byte. A imaginação humana está relacionada à própria capacidade de memória para reter e processar informações passadas e fazer projeções futuras. Já a lexia "byte" pertence ao campo da tecnologia digital e se refere a uma unidade de memória do computador formada por 8 bits. Já a lexia "giga" refere-se a cerca de mil gigabytes de memória de um computador.

$\mathrm{Na}$ criação, a memória humana associa-se à memória de um computador. $\mathrm{O}$ ato de imaginar, pautado na capacidade humana, e o processamento de informação, baseado na memória do computador, interagem no processo de produção de informação e arte. Com o advento de novas tecnologias acessíveis, aliadas às mentes permeadas de imaginação, crescem as possibilidades criativas no campo artístico e literário.

O painel pauta-se no conceito do processo criativo que transcende a noção de original e cópia, fonte e derivação, rearranjando quase por meio de equações matemáticas as combinações das variadas formas de impressão.

A variedade de efeitos de impressão gerada a partir dos registros da placa de policarbonato iluminada permite a apreensão do sentido da criação. A arte sendo contemporânea provoca o apagamento dos limites das noções de original e cópia, pois, todas são possibilidades criativas que partem de um modelo que recebe múltiplos tratamentos de impressões com variados padrões de cores e sombras. Explora-se dessa forma, além das oposições claro e escuro, relações de contrastes através das nuances de cores, apresentando gradações que vão do branco ao bege e do bege ao preto.

As combinações observadas são de escrita clara em fundo escuro, escrita escura em fundo claro, escrita bege em fundo escuro e escrita escura em fundo bege. Portanto, o contraste de cores evidencia a própria escrita poética de maneira criativa. O painel é composto de registros permanentes de um processo efêmero, que parte de uma chapa com orifícios iluminada. A obra é, portanto, concebida no contexto da convergência da arte e mídia e literatura. A imaginação é expandida através de novas tecnologias.

O poema Moondo (2009) foi concebido da seguinte forma: a projeção de "três cabeças de Dedolight, alinhadas paralelamente à parede, projetando três círculos levemente desfocados" que se posicionam no lugar da letra "o" na criação "moondo" (ANTUNES; LAZSLO; SILVEIRA, 2013, p. 95). O filme, revelado por meio de processo E6 normal, foi riscado com estilete pelo próprio poeta. O registro foi feito em meio analógico, em filme Fuji 4x5 Provia $100 \mathrm{~F}$, com lente de $180 \mathrm{~mm}$ e impressão em lambda, na dimensão 127x $160 \mathrm{~cm}$ (ANTUNES; LAZSLO; SILVEIRA, 2013). O projeto possui montagem e fotografia de Lazslo e poema de Arnaldo. 


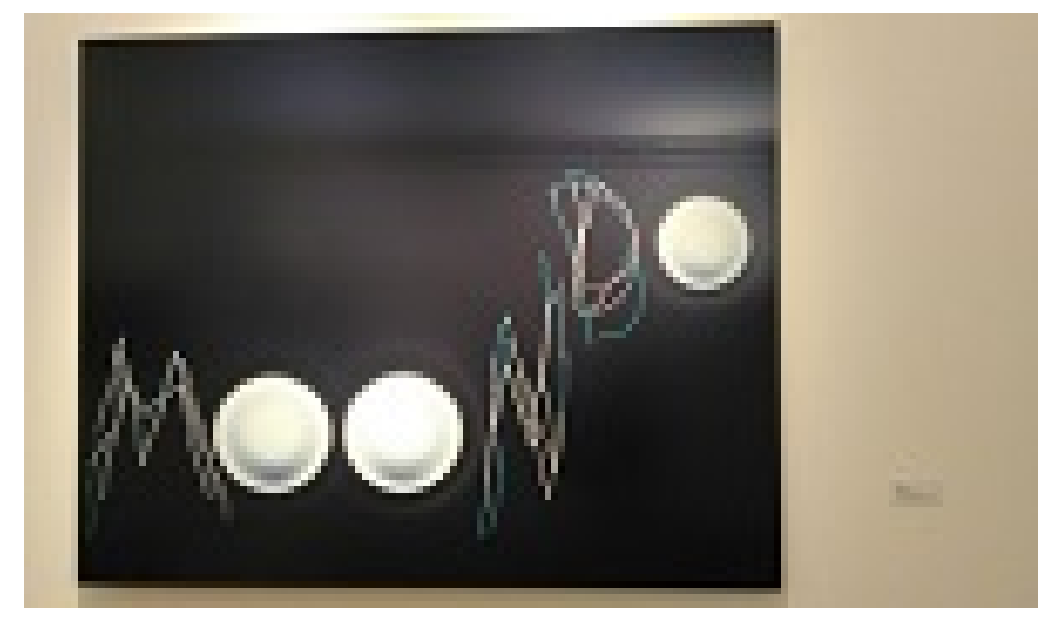

Figura 4. Moondo

Fonte: Acervo pessoal

A criação "moondo" é uma criação neológica resultante do processo de fusão vocabular entre a lexia "mundo", em língua portuguesa, e a lexia em língua inglesa correspondente à lua, "moon": moondo $\leftarrow$ mundo + moon. Portanto, envolve também o uso expressivo do estrangeirismo "moon". A materialidade morfofonológica comum observada em ambas lexias, mundo [mUndu] e moon [mUn], permite a "soldagem" que resulta na criação (CARDOSO, 2016).

Os círculos formados com a projeção de luzes, Figura 4, evidenciam a relação entre o mundo e a lua. A lua remete ao louco, ou ao ser lunático, que habita vários mundos vivendo em uma mesma sociedade. A representação do louco frequentemente é associada ao poeta que sonha com mundos diferentes e amores diversos. Tem-se a relação do homem contemporâneo e a cultura (literatura), a natureza (lua) e a tecnologia (luz), estabelecidas de forma simultânea, em forma de redes através de nós, sem estabelecer oposições.

A obra "Ilumina elimina" foi incluída no evento realizado no Espaço Cultural Porto Seguro em 2017, sendo instalada em um corredor de vidro entre o ambiente da exposição e o elevador. $\mathrm{O}$ painel foi confeccionado em material adesivo reflexivo cobrindo totalmente as dimensões em vidro de $2,20 \mathrm{~m}$. de largura por 2,28 m. de altura e $2,43 \mathrm{~m}$. de largura por $2,80 \mathrm{~m}$. de altura. Sobre este painel espelhado foram feitas aplicações de adesivo preto recortado no formato de lexias variadas. 


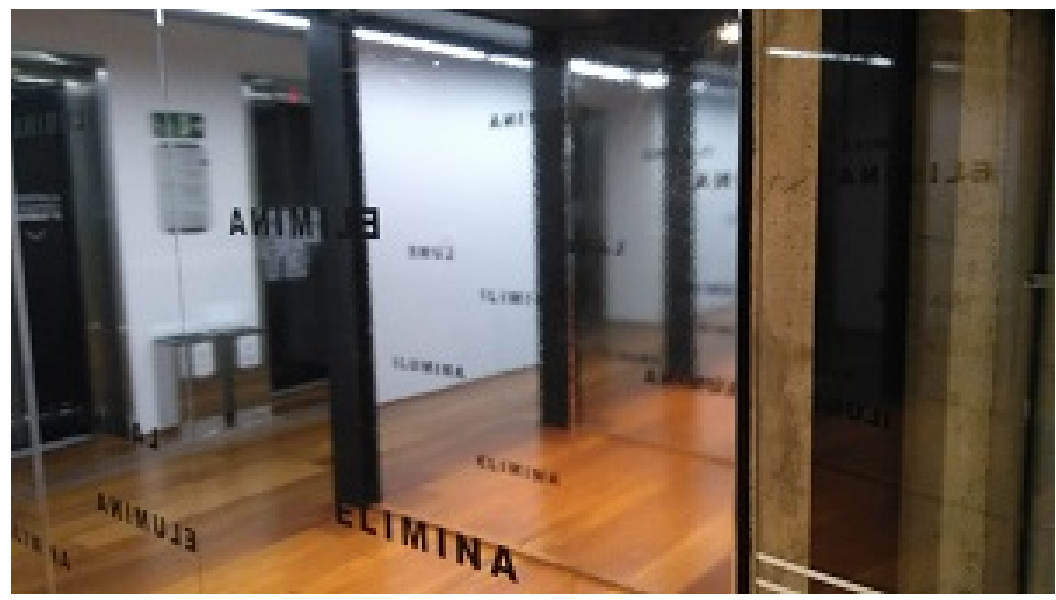

Figura 5. Ilumina elimina

Fonte: Acervo Pessoal

As lexias que compõem a obra a estruturam ritmicamente e visualmente, através de sons aproximados como: Ilumina, elimina, ilimina, lume, elumina, alumina, lamina. A criação "ilimina" é compreendida como resultado de cruzamento vocabular, ilimina $\leftarrow$ ilumina + elimina. O sentido expresso na criação "ilimina" remete ao ato de iluminar que resulta na eliminação de algo.

A criação "elumina" pode também ser compreendida através do processo de cruzamento vocabular, elumina $\leftarrow$ elimina + ilumina. A criação final expressa a ação de eliminar algo, resultando em iluminação.

Portanto, ocorrem duas mesclas conceituais: a presença de luz que elimina ou dissipa algo e a eliminação de algo que resulta em iluminação. Um jogo semântico remete à iluminação, que pode estar associada ao Nirvana budista de superação de si para alcançar a iluminação do espírito. Tal processo dá-se através da eliminação do "eu”, ou ego individualista, em favor de um "eu" que se constitui como parte da grande comunidade humana e universal.

As lexias "lume" e "alumina" possuem aproximação sonora e semântica, podendo ser agrupadas em torno da lexia luz. Já a lexia "lâmina" possui aproximação sonora com as lexias mencionadas, sem possuir relação semântica direta; pode relacionar-se ao material utilizado na instalação como as lâminas espelhadas que refletem a luz, servindo de fundo para a escrita em adesivos pretos. A lexia "lâmina", portanto, estabelece um contraste de sentido com os outros elementos.

O painel reflete um espaço virtual através do material espelhado, estabelecendo uma relação de contraste com o espaço real da exposição, no qual a instalação está inserida, produzindo um resultado expressivo e estético. Tal efeito só ocorre através da presença da luz que reflete entre as paredes espelhadas, permitindo também ao visitante apreciar a sua imagem virtual inserida na obra. 


\section{Conclusão}

Este artigo reuniu um pequeno estudo sobre a palavra no contexto de uma era em que o indivíduo passa a se relacionar de forma mais intensa com a tecnologia. Muito mudou desde o uso da pena e da tinta, contudo, a escolha do meio pelo qual se concebe uma escrita passou a fazer parte diretamente do sentido das criações lexicais.

Ressalta-se que esse relacionamento do ser humano com a tecnologia não exclui a possibilidade da relação com a natureza e a sociedade, pois as conexões são forjadas em rede, formando nós com os mais variados campos de conhecimentos e áreas da vida.

Por fim, há necessidade de escrutínio de um corpus mais abrangente para conclusões mais aprofundadas acerca das criações neológicas em novos contextos. A literatura e as artes imbricam-se cada vez mais através de novos materiais e suportes, possibilitando novos processos criativos.

\section{REFERÊNCIAS}

ANTUNES, A.; LAZSLO, F.; SILVEIRA, W. Luzescrita. Encarte de instalação. Rio de Janeiro: Caixa Cultural, 2013. . Agora aqui ninguém precisa de si. São Paulo: Cia. das Letras, 2015.

BAKHTIN, M. Teoria do romance I: A estilística. Rio de Janeiro: Editora 34, 2015.

BASÍLIO, M. Fusão Vocabular Expressiva: um estudo da produtividade e da criatividade em construções lexicais. Textos selecionados. In: ENCONTRO NACIONAL DA ASSOCIAÇÃO PORTUGUESA DE LINGUÍSTICA, 25, 2010, Porto. Anais eletrônicos... Porto: APL, 2010. Disponível em: <www.apl.org.pt/apl-actas/xv-encontronacional-da-apl.html>. Acesso em: 21 fev. 2016.

CARDOSO, E. A. O léxico no discurso literário: a criatividade lexical na poesia moderna e contemporânea. São Paulo: USP, 2016. (Tese de livre docência não publicada).

CRUTZEN, P. J.; STOERMER, E. F. The Antropocene. Global Change: News Letter, Estocolmo, n. 41, p. 17-18, 2000.

DANTO, A. C. After the end of art: contemporary art and the pale of history. New Jersey: Princeton U. P., 1997.

GONÇALVES, C. A.; ALMEIDA, M. L. Bases semântico-cognitivas para a diferenciação de cruzamentos vocabulares em português. Revista Portuguesa de Humanidades I: Estudos Linguísticos, Braga, v. 11, n. 1, p. 85-95, 2007.

GUILBERT, L. La Créativité lexicale. Paris: Larousse, 1975.

JAMESON, F. Pós-Modernidade e Sociedade de Consumo. Novos Estudos-Cebrap, São Paulo, v. 1, n. 12, p. 16-26, 1985.

LATOUR, B. Reassembling the Social: an introduction to actor-network-theory. Oxford: Oxford U. P., 2005.

RANGEL, D. Luzescrita: Poesias escritas com Luz. In: ANTUNES, A.; LAZSLO, F.; SILVEIRA, W. Luzescrita. Encarte de instalação. Rio de Janeiro: Caixa Cultural, 2013. 
SANTAELLA, L. Abrir Alas para a Luz. In: ANTUNES, A.; LAZSLO, F.; SILVEIRA, W. Luzescrita. Encarte de instalação. Rio de Janeiro: Caixa Cultural, 2013.

ZALASIEWICZ, J. et al. Are we living in the Anthropocene? GSA Today, Vancouver, v. 18, n. 2, p. 4, 2008.

The new world of the Anthropocene. Environment Science \& Technology, Vancouver, v. 44, n. 7, p. 2.228, 2010.

Recebido em: 12/08/2017

Aprovado em: 21/03/2018 